\title{
Philippe Levillain, La papauté foudroyée. La face cachée d'une renonciation
}

Paris, Éditions Tallandier, 2015, 254 p.

Jacques Palard

\section{(2) OpenEdition}

\section{Journals}

Édition électronique

URL : http://journals.openedition.org/assr/28293

DOI : $10.4000 /$ assr.28293

ISSN : $1777-5825$

Éditeur

Éditions de l'EHESS

Édition imprimée

Date de publication : 31 décembre 2016

Pagination : 349

ISSN : 0335-5985

Référence électronique

Jacques Palard, «Philippe Levillain, La papauté foudroyée. La face cachée d'une renonciation », Archives de sciences sociales des religions [En ligne], 176 | octobre-décembre 2016, mis en ligne le 20 juillet 2017, consulté le 24 septembre 2020. URL : http://journals.openedition.org/assr/28293 ; DOI : https://doi.org/10.4000/assr.28293

Ce document a été généré automatiquement le 24 septembre 2020.

(c) Archives de sciences sociales des religions 


\title{
Philippe Levillain, La papauté foudroyée. La face cachée d'une renonciation
}

\author{
Paris, Éditions Tallandier, 2015, 254 p.
}

\author{
Jacques Palard
}

\section{RÉFÉRENCE}

Philippe Levillain, La papauté foudroyée. La face cachée d'une renonciation, Paris, Éditions Tallandier, 2015, $254 \mathrm{p}$.

1 Vaticanologue émérite - plutôt que "vaticaniste ", dont les vues sont estimées moins «amples» (p. 28)-, Philippe Levillain nous offre une mise en perspective historique foisonnante et richement documentée de l'acte de renonciation du pape Benoît XVI «au ministère d'Évêque de Rome, Successeur de saint Pierre» (Déclaration du 11 février 2013 devant les cardinaux réunis en Consistoire, en annexe II de l'ouvrage, p. 225). Le choix du titre de l'ouvrage et de la fort suggestive photo de couverture tire profit d'une étonnante coïncidence - mais en est-ce véritablement une ?-: ce même jour, à la suite de cette annonce détonante, la foudre est spectaculairement tombée sur Saint-Pierre.

2 L'auteur prend plaisir à construire un plan d'enquête et à ouvrir plusieurs dossiers (canonique, théologique, psychologique, organisationnel, financier), afin de permettre au lecteur d'inscrire cet événement quasi inédit dans un large panorama censé lui fournir plusieurs clés de lecture et lui donner ainsi les moyens d'élaborer sa propre interprétation. Il s'agit en effet de répondre à « la grande question : pourquoi ? au pluriel, si l'on ose dire » et de proposer « quelques réponses» (p. 19). Ces réponses, qui sont énoncées de façon manifeste ou latente, portent à penser que la décision de celui qui fut auparavant, et pendant un quart de siècle, le préfet de la Congrégation pour la doctrine de la foi (poste dont il avait demandé dès 2012, mais en vain, de démissionner) 
tient au moins autant à des raisons institutionnelles qu'à des motifs strictement personnels. D'emblée, Levillain affirme d'ailleurs que "l'acte de Benoît XVI est nécessairement le résultat d'un ensemble de mises en cause de l'Église romaine » (p.17), mises en cause qui sont sans doute supposées constituer la «face cachée » de l'événement.

3 L'auteur ouvre les portes de la salle du conclave d'avril 2005, qui suit la mort de JeanPaul II, et situe le rapport de forces entre les deux cardinaux qui restent en lice au terme du troisième tour. Compte tenu du mode de scrutin qui fixe la majorité requise aux deux tiers des voix, le cardinal Bergoglio, qui sera élu huit ans plus tard, bénéficie d'une minorité de blocage, dont il ne jouera pas. L'héritage qui se pose alors sur les épaules de Benoît XVI est particulièrement pesant. Levillain estime que la plus grave erreur de son pontificat aura été de céder à l'injonction du "Santo Subito » crié par les Focolari au moment des obsèques de Jean-Paul II, et d'ouvrir le procès en béatification de son prédécesseur deux mois seulement après son élection. L'analyse de la fabrication des bienheureux et des saints est l'occasion pour l'auteur de revenir sur la béatification par Jean-Paul II des papes si différents que furent, à un siècle d'intervalle, Pie IX et Jean XXIII.

4 La couronne de Benoît XVI ne manque pas d'épines. Désireux de mettre fin au schisme provoqué par Mgr Lefebvre, le pape lève en janvier 2009 les excommunications prononcées neuf ans plus tôt par le Saint-Siège à l'encontre de la consécration épiscopale de quatre prêtres de la Fraternité sacerdotale Saint-Pie-X. Toutefois, ce geste de réconciliation bénéficie de facto à Mgr Williamson, qui avait pourtant déclaré quelques mois plus tôt que l'holocauste était un mythe. Benoît XVI a eu également à faire face au dérèglement de la Congrégation des légionnaires du Christ, dont le fondateur bénéficiait de solides appuis au Vatican, mais dont l'imposture fut néanmoins officiellement reconnue, le contraignant à abandonner tout ministère public. Une place à part est accordée à l'affaire "Vatileaks », qui prit la forme de la publication de deux ouvrages publiés respectivement en 2009 et en 2012 et qui a notamment dévoilé les pratiques financières répréhensibles de la Banque du Vatican et les comportements sexuels de certains membres de la Curie, instance qui « apparaissait à la fois comme l'acteur et la victime du scandale » (p. 185). L'examen de la question des finances ouvre la voie à un large retour historique qui permet d'élucider ce que furent les divers modes de constitution du patrimoine immobilier et mobilier du Saint-Siège au cours des pontificats successifs depuis la seconde moitié du XIx ${ }^{e}$ siècle. On y retrouve, pour la période contemporaine, des noms qui ont défrayé la chronique, comme la Banco Ambrosiano ou Mgr Marcinkus. L'auteur observe, sans nul doute avec réalisme, que "toucher aux finances du Vatican et du Saint-Siège revient à s'engager dans la Vallée de la Mort » (p. 123). On est également porté à le suivre lorsqu'il évoque la campagne de presse lancée par le Banco di Roma, alors présidé par Ernesto Pacelli, cousin au deuxième degré du futur pape Pie XII, et destinée à encourager l'entrée en guerre de l'Italie contre la Turquie en vue de s'assurer un solide établissement en Libye. Par ailleurs, Léon XIII disposait d'un important compte personnel dans cet établissement fondé à Rome en 1880.

5 Le chapitre 5 , consacré à Célestin $\mathrm{V}$, occupe, à tous égards, une position centrale dans l'ouvrage. Le rapprochement avec la personnalité de Benoît XVI tient à la renonciation de ce pape, le bénédictin à l'étonnant destin, San Pietro del Morrone, qui est élu le 5 juillet 1294, à l'âge de 85 ans, et « renonce » à l'exercice de ses fonctions pontificales 
165 jours plus tard. Il sera canonisé dès 1313 par son successeur, le Girondin Bertrand de Got devenu Clément V. Selon l'auteur, la renonciation de Célestin V est exemplaire et préfiguratrice en ce qu'elle est au croisement de considérations à la fois politiques et personnelles. Pourquoi établir un tel parallèle entre les deux seules véritables renonciations dans l'histoire de la papauté ? D'abord en raison de cette relative similarité des motivations, mais aussi et surtout du fait de l'indiscutable vénération qu'à vouée Benoît XVI à son lointain prédécesseur. Le successeur de Jean-Paul II s'est ainsi rendu à Salmona le 4 juillet 2012 pour le "pardon de Célestin V ", dont il a alors célébré la sainteté et la fécondité pastorale. Les chapitres suivants retracent l'activité de Benoît XVI du $1^{\text {er }}$ au 28 février 2013 puis le conclave des 12 et 13 mars, qui aboutira à l'élection de François «le téméraire», «qui n'aime pas Rome» (p.212), la centralisatrice et la conservatrice.

L'ouvrage présente l'insigne mérite de restaurer un climat, celui d'une organisation romaine plus puissante en apparence qu'en réalité parce que chargée d'un passé - un passif? - et d'intérêts qui contribuent à bloquer toute innovation notable. Curialiste lucide, mais en partie marginal et, plus encore, demeuré professeur dans l'âme, Benoît XVI paya en définitive le prix de son désir de réforme en matière tout à la fois financière et morale. L'auteur s'emploie à traiter sa renonciation à la façon de ce que l'on pourrait dénommer un « analyseur institutionnel » propre à révéler l'ensemble des facettes, anciennes et nouvelles, du Saint-Siège. Ce faisant, il ne s'interdit pas quelques clins d'œil, par exemple lorsqu'il définit la modernité par une formule ramassée : «la fragmentation sociale et l'obsession de soi » (p. 138). 